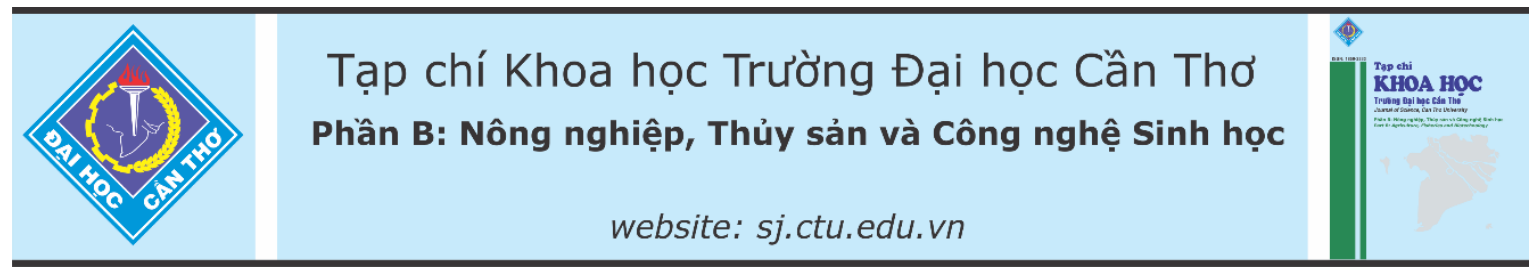

DOI:10.22144/ctu.jvn.2021.052

\title{
NGHIÊN CÚU BỔ SUNG ĐƯờnG CÁT Ở CÁC GIAI ĐOẠN KHÁC NHAU TRONG ƯƠNG ẤU TRÙNG TÔM CÀNG XANH (Macrobrachium rosenbergii) BÄNG CÔNG NGHỆ BIOFLOC
}

\author{
Phạm Minh Truyền ${ }^{1}$, Châu Tài Tảo ${ }^{2}$, Nguyễn Văn Hòa $^{2}$ và Trần Ngọc Hải ${ }^{*}$ \\ ${ }^{I}$ Nghiên cứu sinh nuôi trồng thủy sản Khóa 2017, Khoa Thủy sản, Truờng Đại học Cần Tho \\ ${ }^{2}$ Khoa Thủy sản, Truòng Đại học Cần Tho \\ *Nguoòi chịu trách nhiệm về bài viết: Trần Ngọc Hải (email: tnhai@ctu.edu.vn)
}

\section{Thông tin chung:}

Ngày nhận bài: 03/11/2020

Ngày nhận bài sửa: $18 / 12 / 2020$

Ngày duyệt đăng: 28/04/2021

Title:

Study on nursing giant freshwater prawn

(Macrobrachium rosenbergii)

larvae applying biofloc

technology by supplementation

of sugar at different stages

\section{Tù khóa:}

Áu trùng tôm càng xanh, Biofloc, bổ sung đường cát

\section{Keywords:}

Biofloc, larval of giant

freshwater prawn,

supplementation of sugar

\begin{abstract}
The study is aimed to evaluate the effect of supplementation of sugar at different stages on growth and survival of giant freshwater prawn of larvae and postlarvae applied biofloc technology. The experiment included four treatments of sugar supplement from different stages of larvae (2nd, 4th, 6th, 8 th), each treatment was triplicated, stocking density was 60 ind/liter and water salinity was $12 \%$, the experimental tank was $0.5 \mathrm{~m}^{3}$ in volume. The results showed that the metamorphism index of the larvae after 21 days of incubation (10.70 \pm 0.10$)$, the length of the postlarvae $15(11.4 \pm 0.1 \mathrm{~mm})$ of the treatment with sugar supplement at stage 4 were significantly different $(p<0.05)$ from those of other treatments. The survival rate $(55.3 \pm 1.9 \%)$ and yield $\left(33,160 \pm 1,153 \mathrm{ind} / \mathrm{m}^{3}\right)$ of postlarvae 15 , in which the treatment of adding sugar from stage 4 was not significant $(p>0.05)$ compared with the treatment of adding sugar from stage 6, but the difference was statistically significant $(p<0.05)$ compared to the other treatments. It can be concluded that supplement of sugar at stage 4 is the best among the treatments studied in rearing rearing giant freshwater prawn larvae using biofloc technology.
\end{abstract}

\section{TÓM TẮT}

Nghiên cứu nhằm đánh giá ảnh hưởng của bổ sung đường cát ở các giai đoạn khác nhau lên tăng trưởng và tỷ lẹ sống của ấu trùng và hậu ấu trùng tôm càng xanh ương theo công nghệ biofloc. Thi nghiệm được bố trí hoàn toàn ngẫu nhiên 3 lần lặp lại với 4 nghiệm thức: (i) bổ sung đường cát tù giai đoạn 2 (ii) bổ sung đường cát tù giai đoạn 4 (iii) bổ sung đường cát tù̀ giai đoạn 6 và (iv) bổ sung đường cát tù giai đoạn 8 của ấu trùng. Bể uoong tôm có thể tich $0,5 \mathrm{~m}^{3}$, mật độ 60 con/lit, độ mặn 12\%. Kết quả nghiên cứu cho thấy chỉ số biến thái của ấu trùng sau 21 ngày uơng $(10,70 \pm 0,10)$, chiều dài của postlarvae $15(11,4 \pm 0,1 \mathrm{~mm})$ ở nghiệm thức bổ sung đường cát tù giai đoạn 4 khác biệt có ý nghĩa thống kê $(p<0,05)$ so với các nghiệm thức còn lại. Tỷ lẹ sống $(55,3 \pm 1,9 \%)$ và năng suất $\left(33.160 \pm 1.153 \mathrm{con} / \mathrm{m}^{3}\right)$ của postlarvae 15 ở nghiệm thức bổ sung đường cát tù giai đoạn 4 khác biệt không có ý nghĩa thống kê $(p>0,05)$ so với nghiệm thức bổ sung đường cát tù giai đoạn 6 , nhưng khác biệt có ý nghĩa thống kê $(p<0,05)$ so với các nghiệm thức cò̀ lại. Có thể kết luận rằng ương ấu trùng tôm càng xanh theo công nghệ biofloc bổ sung đường cát tù giai đoạn 4 là tốt nhất. 


\section{GIỚI THIỆU}

Hiện nay tôm càng xanh là một trong những đối tượng nuôi phổ biến trên thế giới. Ở Việt Nam, Đồng Bằng Sông Cửu Long là vùng trọng điểm nuôi tôm càng xanh của cả nước. Theo báo cáo của Tổng cục Thủy sản (2018), tổng diện tích nuôi tôm càng xanh là 30.000 ha (tăng 15.000 ha so với năm 2014), sản lượng nuôi đạt 30.000 tấn. Theo kế hoạch đến năm 2020 sẽ phát triển nuôi 127.850 ha, với lượng giống cần 2-3 tỷ con giống (Tổng cục Thủy sản, 2018). Trước tình hình đó, để tìm được giải pháp cho nghề sản xuất giống tôm càng xanh theo hướng an toàn sinh học, việc ứng dụng công nghệ biofloc trong ương ấu trùng tôm càng xanh để tạo ra con giống chất lượng cao phục vụ cho nghề nuôi là rất cần thiết. Công nghệ biofloc được ứng dụng trong nuôi trồng thủy sản là một giải pháp hữu hiệu để cải thiện môi trường nước và là nguồn thức ăn tốt cho đối tượng nuôi (Avnimelech, 2012; De Schryver et al., 2008). Hiện nay có một số nghiên cứu ương ấu trùng tôm càng xanh theo công nghệ biofloc như bổ sung các nguồn carbon khác nhau (Lê Thanh Nghị và ctv. 2020), bổ sung đường cát vơi tỷ lệ $\mathrm{C} / \mathrm{N}$ khác nhau (Phạm Minh Truyền và ctv. 2020), nhưng để xác định được thời điểm bổ sung đường cát từ giai đoạn mấy của ấu trùng là tốt nhất để ấu trùng và hậu ấu trùng tăng trưởng tốt và tỷ lệ sống cao là rất cần thiết nhằm xây dựng qui trình ương ấu trùng tôm càng xanh bằng công nghệ biofloc để ứng dụng vào thực tế sản xuất.

\section{PHƯƠNG PHÁP NGHIÊN CÚU}

\subsection{Nguồn nước thí nghiệm}

Nguồn nước thí nghiệm được lấy từ nguồn nước ngọt (nước máy thành phố) pha với nước ót (độ mặn từ $80-100 \%$ được lấy từ ruộng muối ở huyện Vĩnh Châu, tỉnh Sóc Trăng), để tạo thành nước có độ mặn $12 \%$ sau đó được xử lý bằng chlorine với nồng độ $50 \mathrm{~g} / \mathrm{m}^{3}$, sục khí mạnh cho hết lượng chlorine trong nước, tiếp theo dùng sodium bicarbonate nâng độ kiềm lên $120 \mathrm{mgCaCO}_{3} / \mathrm{L}$ và cuối cùng bơm qua ống vi lọc $1 \mu \mathrm{m}$ trước khi sử dụng.

\subsection{Nguồn ấu trùng tôm càng xanh}

Chọn tôm càng xanh mẹ mang trứng màu xám đen, chất lượng tốt, khỏe mạnh, kích cỡ từ 50-80 g/con, màu sắc tươi sáng cho vào bể ấp nở có thể tích $500 \mathrm{~L}$, độ mặn 12\%o. Sau khi trứng nở thành ấu trùng, chọn ấu trùng có tính hướng quang mạnh để bố trí thí nghiệm.

\subsection{Tạo biofloc}

Biofloc được tạo bằng nguồn carbon từ đường cát (Biên Hòa Pure) với các tỷ lệ $\mathrm{C} / \mathrm{N}=17,5$ (Phạm Minh Truyền và ctv, 2020), đường cát có $55,54 \% \mathrm{C}$ được phân tích ở Trung tâm kỹ thuật tiêu chuẩn đo lường chất lượng Cần Thơ. Đường cát được pha bằng nước ấm $60^{\circ} \mathrm{C}$, với tỷ lệ $1: 3$ (1 đường: 3 nước theo khối lượng), khuấy đều và ủ trong 48 giờ trước khi cho vào bể ương tôm. Phương thức bổ sung đường cát dựa theo lượng thức ăn nhân tạo sử dụng là Lansy $\mathrm{PL}$ có $48 \%$ protein, đường cát được bổ sung 1 ngày một lần dựa trên lượng thức ăn cho tôm trong ngày. Lượng đường cát cần bổ sung vào bể để tạo biofloc được tính dựa theo công thức của Avnimelech (2015).

\subsection{Bố trí thí nghiệm}

Thí nghiệm gồm 4 nghiệm thức bổ sung đường cát ở các giai đoạn ấu trùng khác nhau, cách bố trí hoàn toàn ngẫu nhiên, lặp lại 3 lần, bể ương bằng composite $500 \mathrm{~L}$, độ mặn $12 \%$, mật độ ấu trùng 60 $\operatorname{con} / \mathrm{L}$.

- Nghiệm thức 1: Bổ sung đường cát từ giai đoạn 2 của ấu trùng

- Nghiệm thức 2: Bổ sung đường cát từ giai đoạn 4 của ấu trùng

- Nghiệm thức 3: Bổ sung đường cát từ giai đoạn 6 của ấu trùng

- Nghiệm thức 4: Bổ sung đường cát từ giai đoạn 8 của ấu trùng

\subsection{Chăm sóc và quản lý ấu trùng tôm càng xanh}

Hằng ngày theo dõi hoạt động bơi lội của ấu trùng và lượng thức ăn cho ấu trùng ăn. Âu trùng tôm càng xanh được chăm sóc và cho ăn theo Bảng 1. Trong thời gian ương không thay nước, sục khí liên tục để đảm bảo sự lơ lửng của hạt biofloc. 
Bảng 1. Công thức thức ăn chế biến cho ấu trùng tôm càng xanh

\begin{tabular}{|c|c|c|c|}
\hline Giai đoạn ấu trùng & Loại thức ăn & Lượng thức ăn & Số lần cho ăn \\
\hline Giai đoạn 1 & \multicolumn{3}{|c|}{ Không cho ăn } \\
\hline $\begin{array}{l}\text { Giai đoạn } \\
2-3\end{array}$ & $\begin{array}{l}\text { Âu trùng (AT) } \\
\text { Artemia }\end{array}$ & $\begin{array}{l}1 \text { AT Artemia/mL } \\
\text { nước ương }\end{array}$ & $\begin{array}{l}2 \text { lần/ngày } \\
\text { (7giờ và } 17 \text { giờ) }\end{array}$ \\
\hline $\begin{array}{l}\text { Giai đoạn } \\
4-5\end{array}$ & $\begin{array}{l}\text { Thức ăn Lansy PL } \\
\text { Âu trùng Artemia }\end{array}$ & $\begin{array}{l}1 \mathrm{~g} / \mathrm{m}^{3} / \mathrm{lần} \\
3 \mathrm{AT} \text { Artemia } / \mathrm{mL} \\
\text { nước ương }\end{array}$ & $\begin{array}{l}3 \text { lần/ngày (8giờ, 11 giờ và 14giờ) } \\
1 \text { lần/ngày (17giờ) }\end{array}$ \\
\hline $\begin{array}{l}\text { Giai đoạn } \\
6-8\end{array}$ & $\begin{array}{l}\text { Thức ăn Lansy PL } \\
\text { Âu trùng Artemia }\end{array}$ & $\begin{array}{l}1,5 \mathrm{~g} / \mathrm{m}^{3} / / \text { làn } \\
3 \mathrm{AT} \text { Artemia } / \mathrm{mL} \\
\text { nước ương }\end{array}$ & $\begin{array}{l}3 \text { lần/ngày (8 giờ, 11 giờ và 14giờ) } \\
1 \text { lần/ngày (17giờ) }\end{array}$ \\
\hline $\begin{array}{l}\text { Giai đoạn } \\
9 \text { - PL15 }\end{array}$ & $\begin{array}{l}\text { Thức ăn Lansy PL } \\
\text { Âu trùng Artemia }\end{array}$ & $\begin{array}{l}2 \mathrm{~g} / \mathrm{m}^{3} / \mathrm{lần} \\
4 \mathrm{AT} \text { Artemia } / \mathrm{mL} \\
\text { nước ương }\end{array}$ & $\begin{array}{l}3 \text { lần/ngày (8giờ, 11 giờ và 14giờ) } \\
1 \text { lần/ngày (17giờ) }\end{array}$ \\
\hline
\end{tabular}

\subsection{Các chỉ tiêu theo dõi và thu mẫu phân tích}

- Chỉ tiêu môi trường nước: Nhiệt độ đo bằng nhiệt kế, $\mathrm{pH}$ đo bằng máy đo $\mathrm{pH}$, các chỉ tiêu này đo 2 lần/ngày ( 8 giờ và 14 giờ). Độ kiềm, $\mathrm{TAN}$ và $\mathrm{NO}_{2}{ }^{-}$ định kỳ thu mẫu 7 ngày/lần. Độ kiềm được phân tích theo phương pháp chuẩn độ acid, TAN được phân tích theo phương pháp Indophenol Blue, $\mathrm{NO}_{2}{ }^{-}$được phân tích theo phương pháp so màu $4500-\mathrm{NO}_{2}{ }^{-} \mathrm{B}$ (APHA et al., 1995)

- Các chỉ tiêu theo dõi tôm: Chỉ số biến thái của ấu trùng (LSI) được xác định 3 ngày/1 lần, mỗi lần thu ngẫu nhiên 10 ấu trùng/bể, chỉ số biến thái của ấu trùng tôm càng xanh theo dõi đến ngày thứ 21. Chiều dài ấu trùng và hậu ấu trùng được đo ở các giai đoạn $1,5,11$, PL-1 và PL-15, mỗi lần đo 30 con/bể. Tỷ lệ sống và sinh khối của PL-15 được tính bằng phương pháp định lượng khối lượng tôm từ đó xác định được số tôm trong bể.

- Chỉ tiêu vi sinh: Tổng vi khuẩn và vi khuẩn Vibrio trong nước, được xác định 15 ngày/lần. Tổng vi khuẩn và vi khuẩn Vibrio trong tôm được xác định cuối thí nghiệm. Xác định mật độ vi khuẩn theo phương pháp của Huys (2002).

- Chỉ tiêu biofloc: Thể tích biofloc (FV) được xác định khi bể ương có tôm ở giai đoạn PL-5, PL10 và $P L-15$ bằng bình imhoff, xác định kích cỡ hạt biofloc bằng cách đo chiều dài và chiều rộng ngẫu nhiên 10 hạt biofloc dưới kính hiển vi có trắc vi thị kính.

\subsection{Phương pháp xử lý số liệu}

Các số liệu thu thập được tính toán các giá trị trung bình, độ lệch chuần bằng phần mềm Microsoft Excel 2013, so sánh sự khác biệt giữa các nghiệm thức theo phương pháp phân tích ANOVA một nhân tố với phép thử Duncan bằng phần mềm thống kê SPSS 22.0 ở mức ý nghĩa $(\mathrm{p}<0,05)$.

\section{KẾT QUẢ VÀ THẢO LUẬN}

\subsection{Biến động các yếu tố thủy lý hóa trong bể ương}

Nhiệt độ buổi sáng và buổi chiều giữa các nghiệm thức được trình bày ở Bảng 2 , nhiệt độ buổi sáng dao động từ $29,4-29,6^{\circ} \mathrm{C}$, và buổi chiều từ $30,9-31,3{ }^{\circ} \mathrm{C}$. Theo Đỗ Thị Thanh Hương và Nguyễn Văn Tư (2010), nhiệt độ thích hợp cho tôm càng xanh từ $26-32^{\circ} \mathrm{C}$, nếu nhiệt độ quá cao hoặc quá thấp sẽ ảnh hưởng đến hoạt động, sinh trưởng, sinh sản của tôm sẽ bị suy giảm hay chết. Vậy nhiệt độ của các bể thí nghiệm trong khoảng thích hợp cho tôm càng xanh phát triển tốt.

Trung bình $\mathrm{pH}$ ở các nghiệm thức biến động rất nhỏ, buổi sáng $\mathrm{pH}$ từ 8,11 đến 8,12 và buổi chiều 8,25 đến 8,27 . pH dao động từ 7,5 - 9 nằm trong khoảng thích hợp cho ương giống tôm càng xanh (Boyd \& Zimmermann, 2000; Sandifer \& Smith, 1985). Như vậy giá trị $\mathrm{pH}$ của thí nghiệm nằm trong khoảng giới hạn cho phép nên không ảnh hưởng đến sinh trưởng của tôm.

Độ kiềm trung bình từ 115,4 đến 119,3 $\mathrm{mgCaCO}_{3} / \mathrm{L}$. Theo Châu Tài Tảo và ctv. (2015), độ kiềm thích hợp cho ấu trùng và hậu ấu trùng tôm càng xanh là $100-120 \mathrm{mgCaCO}_{3} / \mathrm{L}$. Vì vậy độ kiềm của các nghiệm thức thích hợp cho tôm phát triển tốt.

Hàm lượng TAN trung bình ở các nghiệm thức dao động từ $0,47-0,77 \mathrm{mg} / \mathrm{L}$, thấp nhất là ở nghiệm thức bồ sung đường cát từ giai đoạn 2 khác biệt không có ý nghĩa thống kê $(\mathrm{p}>0,05)$ so với nghiệm thức bổ sung đường cát từ giai đoạn 4 , nhưng khác biệt có ý nghĩa thống kê $(\mathrm{p}<0,05)$ so với các nghiệm thức còn lại. Ang (1985) cho rằng ương ấu trùng tôm càng xanh hàm lượng TAN $>2,5 \mathrm{mg} / \mathrm{L}$ nhưng âu trùng tôm càng xanh dẫn phát triển tốt. Vậy, hàm 
lượng TAN ở các nghiệm thức đều thích hợp cho tôm phát triển.

Hàm lượng nitrit biến động trong khoảng 0,18 $0,37 \mathrm{mg} / \mathrm{L}$, cao nhất ở nghiệm thức bổ sung đường cát từ giai đoạn 8 khác biệt không có ý nghĩa thống kê $(\mathrm{p}>0,05)$ so với nghiệm thức bổ sung đường cát từ giai đoạn 6 , nhưng khác biệt có ý nghĩa thống kê $(\mathrm{p}<0,05)$ so với các nghiệm thức còn lại, theo ghi nhận của Margarete and Wagner (2006), tỷ lệ sống, tăng trưởng và chỉ số biến thái không có sự khác biệt khi ấu trùng tôm càng xanh được ương ở mức $\mathrm{NO}_{2}{ }^{-}$

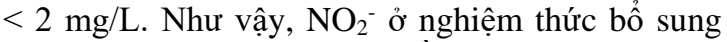
đường cát ở giai đoạn 2 và 4 nằm trong phạm vi cho phép để tôm phát triển tốt, tuy nhiên ở nghiệm thức bổ sung đường cát ở giai đoạn 6 và 8 đến cuối thí nghiệm hàm lượng TAN và $\mathrm{NO}_{2}^{-}$cao hơn khoảng cho phép nên đã ảnh hưởng đến tỷ lệ sống của tôm.

Bảng 2. Trung bình các yếu tố môi trường của các nghiệm thức

\begin{tabular}{|c|c|c|c|c|c|}
\hline \multirow{2}{*}{\multicolumn{2}{|c|}{ Chỉ tiêu }} & \multicolumn{4}{|c|}{ Giai đoạn bổ sung đường cát } \\
\hline & & 2 & 4 & 6 & 8 \\
\hline \multirow{2}{*}{$\begin{array}{l}\text { Nhiệt độ } \\
\left({ }^{\circ} \mathrm{C}\right)\end{array}$} & Sáng & $29,6 \pm 0,3$ & $29,7 \pm 0,1$ & $29,5 \pm 0,1$ & $29,4 \pm 0,1$ \\
\hline & Chiều & $31,0 \pm 0,4$ & $31,3 \pm 0,5$ & $30,9 \pm 0,3$ & $31,1 \pm 0,1$ \\
\hline & Sáng & $8,11 \pm 0,03$ & $8,12 \pm 0,01$ & $8,12 \pm 0,03$ & $8,11 \pm 0,02$ \\
\hline & Chiều & $8,25 \pm 0,04$ & $8,26 \pm 0,02$ & $8,27 \pm 0,05$ & $8,26 \pm 0,03$ \\
\hline \multirow{3}{*}{\multicolumn{2}{|c|}{$\begin{array}{l}\text { Độ kiềm }\left(\mathrm{mgCaCO}_{3} / \mathrm{L}\right) \\
\text { TÂN }(\mathrm{mg} / \mathrm{L}) \\
\mathrm{NO}_{2}^{-}(\mathrm{mg} / \mathrm{L})\end{array}$}} & $117,3 \pm 6,21$ & $119,3 \pm 2,9$ & $115,4 \pm 6,2$ & $119,3 \pm 5,2$ \\
\hline & & $0,47 \pm 0,08^{\mathrm{a}}$ & $0,49 \pm 0,10^{\mathrm{a}}$ & $0,72 \pm 0,20^{\mathrm{b}}$ & $0,77 \pm 0,13^{b}$ \\
\hline & & $0,18 \pm 0,04^{\mathrm{a}}$ & $0,24 \pm 0,06^{\mathrm{a}}$ & $0,34 \pm 0,02^{\mathrm{b}}$ & $0,37 \pm 0,02^{b}$ \\
\hline
\end{tabular}

Các giá trị cùng một hàng có kí tự giống nhau thì khác biệt không có ý nghĩa thống kê $(p>0,05)$

\subsection{Các chỉ tiêu về biofloc}

Ở giai đoạn PL-5, thể tích biofloc cao nhất ở nghiệm thức bổ sung đường cát từ giai đoạn 2 và khác biệt có ý nghĩa thống kê $(\mathrm{p}<0,05)$ so với nghiệm thức bổ sung đường cát từ giai đoạn 8 , nhưng khác biệt không có ý nghĩa thống kê so với các nghiệm thức còn lại. Đến giai đoạn PL-10 và PL-15 thể tích biofloc cao nhất vẫn là ở nghiệm thức bổ sung đường cát từ giai đoạn 2 khác biệt không có ý nghĩa thống kê $(\mathrm{p}>0,05)$ so với nghiệm thức bổ sung đường cát từ giai đoạn 4 , nhưng khác biệt có ý nghĩa thống kê $(\mathrm{p}<0,05)$ so với 2 nghiệm thức còn lại.

Chiều dài và chiều rộng hạt biofloc được trình bày ở Bảng 3. Kết quả xử lý thống kê cho thấy qua các lần thu mẫu chiều dài và chiều rộng hạt biofloc của các nghiệm thức khác biệt không có ý nghĩa thống kê $(\mathrm{p}>0,05)$.

\section{Bảng 3. Thể tích và kích thước hạt biofloc của các nghiệm thức}

\begin{tabular}{llrrrr}
\hline \multirow{2}{*}{ Chỉ tiêu } & Giai đoạn & \multicolumn{3}{c}{ Giai đoạn bổ sung đường cát } \\
\cline { 2 - 5 } & thu & $\mathbf{2}$ & $\mathbf{4}$ & $\mathbf{6}$ & $\mathbf{8}$ \\
\hline \multirow{3}{*}{ Thể tích (ml/L) } & PL-5 & $0,37 \pm 0,15^{\mathrm{b}}$ & $0,33 \pm 0,15^{\mathrm{ab}}$ & $0,20 \pm 0,10^{\mathrm{ab}}$ & $0,10 \pm 0,05^{\mathrm{a}}$ \\
& PL-10 & $0,97 \pm 0,21^{\mathrm{b}}$ & $0,90 \pm 0,10^{\mathrm{b}}$ & $0,62 \pm 0,10^{\mathrm{a}}$ & $0,50 \pm 0,10^{\mathrm{a}}$ \\
& PL-15 & $1,60 \pm 0,10^{\mathrm{b}}$ & $1,37 \pm 0,21^{\mathrm{b}}$ & $1,05 \pm 0,13^{\mathrm{a}}$ & $0,90 \pm 0,10^{\mathrm{a}}$ \\
\hline \multirow{3}{*}{ Chiều dài (mm) } & PL-5 & $0,16 \pm 0,01^{\mathrm{a}}$ & $0,15 \pm 0,01^{\mathrm{a}}$ & $0,16 \pm 0,01^{\mathrm{a}}$ & $0,14 \pm 0,01^{\mathrm{a}}$ \\
& PL-10 & $0,27 \pm 0,05^{\mathrm{a}}$ & $0,25 \pm 0,02^{\mathrm{a}}$ & $0,26 \pm 0,08^{\mathrm{a}}$ & $0,24 \pm 0,04^{\mathrm{a}}$ \\
& PL-15 & $0,35 \pm 0,19^{\mathrm{a}}$ & $0,34 \pm 0,29^{\mathrm{a}}$ & $0,32 \pm 0,18^{\mathrm{a}}$ & $0,30 \pm 0,18^{\mathrm{a}}$ \\
\hline \multirow{3}{*}{ Chiều rộng (mm) } & PL-5 & $0,14 \pm 0,01^{\mathrm{a}}$ & $0,12 \pm 0,01^{\mathrm{a}}$ & $0,13 \pm 0,01^{\mathrm{a}}$ & $0,11 \pm 0,01^{\mathrm{a}}$ \\
& PL-10 & $0,24 \pm 0,11^{\mathrm{a}}$ & $0,23 \pm 0,17^{\mathrm{a}}$ & $0,22 \pm 0,03^{\mathrm{a}}$ & $0,20 \pm 0,03^{\mathrm{a}}$ \\
& PL-15 & $0,29 \pm 0,04^{\mathrm{a}}$ & $0,27 \pm 0,15^{\mathrm{a}}$ & $0,26 \pm 0,03^{\mathrm{a}}$ & $0,27 \pm 0,07^{\mathrm{a}}$ \\
\hline
\end{tabular}

Các giá trị cùng một hàng có kí tụ giống nhau thì khác biệt không có ý nghĩa thống kê ( $p>0,05)$

\subsection{Tổng vi khuẩn và Vibrio ở các nghiệm thức}

Mật độ tổng vi khuẩn trong nước ngày thứ 15 dao động từ 9,3 đến $9,7 \times 10^{4} \mathrm{CFU} / \mathrm{mL}$ và cuối thí nghiệm dao động từ 6,3 đến $9,1 \times 10^{4} \mathrm{CFU} / \mathrm{mL}$, khác biệt không có ý nghĩa thống kê $(\mathrm{p}>0,05)$ giữa các nghiệm thức. Theo Phạm Minh Truyền và ctv. (2020), ương ấu trùng tôm càng xanh theo công nghệ biofloc với tỷ lệ $\mathrm{C} / \mathrm{N}$ khác nhau cho thấy mật độ tổng vi khuẩn sau 15 ngày và cuối thí nghiệm lần lượt là 2,4 và $14,3 \times 10^{4} \mathrm{CFU} / \mathrm{mL}$ thì ấu trùng và hậu ấu trùng tôm càng xanh dẫn phát triển tốt. Như vậy 
mật độ tổng vi khuẩn cả 4 nghiệm thức đều nằm trong khoảng thích hợp cho tôm phát triển.

Mật độ tổng vi khuẩn trong tôm thấp nhất ở nghiệm thức bổ sung đường cát từ giai đoạn 2 $\left(14,8 \times 10^{4} \mathrm{CFU} / \mathrm{g}\right)$ khác biệt không có ý nghĩa thống kê $(\mathrm{p}>0,05)$ so với nghiệm thức bổ sung đường cát từ giai đoạn 4 nhưng khác biệt có nghĩa thống kê so với 2 nghiệm thức còn lại. Theo Anderson (1993), trong môi trường nước sạch mật độ tổng vi khuẩn nhỏ hơn $10^{3} \mathrm{CFU} / \mathrm{mL}$, nếu mật độ tổng vi khuẩn vượt quá $10^{7} \mathrm{CFU} / \mathrm{mL}$ sẽ có hại cho tôm cá nuôi và môi trường trở nên bẩn. Như vậy kết quả về mật độ tổng vi khuẩn của nghiên cứu này vẫn nằm trong giới hạn cho phép.

Bảng 4. Mật độ tổng vi khuẩn trong nước $\left(10^{4} \mathrm{CFU} / \mathrm{ml}\right)$ và trong tôm $\left(10^{4} \mathrm{CFU} / \mathrm{g}\right)$

\begin{tabular}{lrrrr}
\hline \multirow{2}{*}{ Chỉ tiêu } & \multicolumn{4}{c}{ Các giai đoạn bổ sung đường cát } \\
\cline { 2 - 5 } & $\mathbf{2}$ & $\mathbf{4}$ & $\mathbf{6}$ & $\mathbf{8}$ \\
\hline Lần 1 (Ngày 15) & $9,7 \pm 2,4^{\mathrm{a}}$ & $6,9 \pm 4,7^{\mathrm{a}}$ & $9,5 \pm 1,2^{\mathrm{a}}$ & $9,3 \pm 0,7^{\mathrm{a}}$ \\
Lần 2 (Cuối thí nghiệm) & $6,3 \pm 0,5^{\mathrm{a}}$ & $7,7 \pm 1,0^{\mathrm{a}}$ & $9,1 \pm 1,1^{\mathrm{a}}$ & $7,2 \pm 3,6^{\mathrm{a}}$ \\
Trong tôm & $14,8 \pm 5,7^{\mathrm{a}}$ & $17,5 \pm 5,3^{\mathrm{a}}$ & $44,2 \pm 1,2^{\mathrm{b}}$ & $52,2 \pm 11,4^{\mathrm{b}}$ \\
\hline
\end{tabular}

Các giá trị cùng một hàng có kí tụ giống nhau thì khác biệt không có ý nghĩa thống kê $(p>0,05)$

Bảng 5 cho thấy sau ngày 15 ương, mật độ vi khuẩn Vibrio ở các nghiệm thức dao động từ $10,9 \times 10^{2}$ đến $22,6 \times 10^{2} \mathrm{CFU} / \mathrm{mL}$. Ở nghiệm thức bổ sung đường cát từ giai đoạn 8 cao nhất và khác biệt không có ý nghĩa thống kê $(\mathrm{p}>0,05)$ so với nghiệm thức bổ sung đường cát từ giai đoạn 6 , nhưng khác biệt có ý nghĩa thống kê $(\mathrm{p}<0,05)$ so với 2 nghiệm thức còn lại. Cuối thí nghiệm, mật độ vi khuẩn
Vibrio thấp nhất ở nghiệm thức bổ sung đường cát từ giai đoạn 2 , khác biệt có ý nghĩa thống kê $(\mathrm{p}<0,05)$ so với nghiệm thức bổ sung đường cát từ giai đoạn 8 , nhưng khác biệt không có ý nghĩa ( $>0,05)$ so với các nghiệm thức còn lại. Do bổ sung đường cát sớm kích thích nhóm vi khuẩn có lợi phát triển trước nên lấn ác vi khuẩn Vibrio dẫn đến mật độ vi khuẩn Vibrio tăng dần khi bổ sung đường cát từ giai đoạn 2 đến giai đoạn 8 .

Bảng 5. Mật độ vi khuẩn Vibrio trong nước $\left(10^{2} \mathrm{CFU} / \mathrm{ml}\right)$ và trong tôm $\left(10^{2} \mathrm{CFU} / \mathrm{g}\right)$

\begin{tabular}{lrrrr}
\hline \multirow{2}{*}{ Chỉ tiêu } & \multicolumn{3}{c}{ Giai đoạn bổ sung đường cát } \\
\cline { 2 - 5 } & $\mathbf{2}$ & $\mathbf{4}$ & $\mathbf{6}$ & $\mathbf{8}$ \\
\hline Lần 1 (Ngày 15) & $10,9 \pm 1,8^{\mathrm{a}}$ & $11,8 \pm 2,8^{\mathrm{a}}$ & $20,1 \pm 2,6^{\mathrm{b}}$ & $22,6 \pm 0,8^{\mathrm{b}}$ \\
Lần 2 (Cuối thí nghiệm) & $24,3 \pm 10,5^{\mathrm{a}}$ & $28,3 \pm 6,6^{\mathrm{a}}$ & $46,3 \pm 7,1^{\mathrm{ab}}$ & $58,0 \pm 21,4^{\mathrm{b}}$ \\
Trong tôm & $11,5 \pm 2,3^{\mathrm{a}}$ & $20,0 \pm 5,2^{\mathrm{a}}$ & $27,4 \pm 9,7^{\mathrm{ab}}$ & $40,0 \pm 15,7^{\mathrm{b}}$ \\
\hline
\end{tabular}

Các giá trị cùng một hàng có kí tư giống nhau thì khác biệt không có ý nghĩa thống kê $(p>0,05)$

Mật độ vi khuẩn Vibrio trong tôm ở các nghiệm thức dao động từ 11,5 đến $40 \times 10^{2} \mathrm{CFU} / \mathrm{g}$. Cao nhất ở nghiệm thức bổ sung đường cát từ giai đoạn 8 $\left(40 \times 10^{2} \mathrm{CFU} / \mathrm{g}\right)$ khác biệt có ý nghĩa thống kê $(p<0,05)$ so với nghiệm thức bổ sung đường cát từ giai đoạn $2\left(11,5 \times 10^{2} \mathrm{CFU} / \mathrm{g}\right)$ và nghiệm thức bổ sung đường cát từ giai đoạn $4\left(20 \times 10^{2} \mathrm{CFU} / \mathrm{g}\right)$ và khác biệt không có ý nghĩa $(p<0,05)$ ở nghiệm thức bổ sung đường cát từ giai đoạn $6\left(27,4 \times 10^{2} \mathrm{CFU} / \mathrm{g}\right)$. Mật độ vi khuẩn Vibrio có xu hướng tăng về giữa thời gian ương càng về cuối mật độ giảm dần do có sự cạnh tranh dinh dưỡng và kìm hãm bởi các loại vi khuẩn có lợi. Theo Phạm Thị Tuyết Ngân và ctv. (2008), mật độ vi khuẩn Vibrio nhỏ hơn $6,5 \times 10^{3}$ $\mathrm{CFU} / \mathrm{mL}$ chưa gây ảnh hưởng đến tôm nuôi. Vậy mật độ vi khuẩn Vibrio trong thí nghiệm này không ảnh hưởng xấu đến ấu trùng và hậu ấu trùng tôm.

\subsection{Chỉ số biến thái LSI}

Chỉ số LSI thể hiện sự biến thái và mức độ đồng đều của ấu trùng tôm càng xanh trong bể ương. Sự phát triển của ấu trùng tôm càng xanh được thông qua chu kì lột xác và biến thái. Âu trùng trải qua 11 lần lột xác và biến thái để hình thành hậu ấu trùng (Nguyễn Thanh Phương và ctv., 2003). Tuy nhiên, thời gian lột xác mỗi giai đoạn tùy thuộc vào điều kiện môi trường, dinh dưỡng, giới tính, mật độ ương và kiều kiện sinh lý của chúng. Bảng 6 cho thấy chỉ số biến thái tôm càng xanh từ ngày 3 đến ngày 18 khác biệt không có ý nghĩa thống kê $(\mathrm{p}>0,05)$ giữa các nghiệm thức. Đến ngày ương thứ 21 , chỉ số biến thái của ấu trùng tôm càng xanh cao nhất ở nghiệm thức bổ sung đường cát từ giai đoạn 4 và khác biệt có ý nghĩa thống kê $(\mathrm{p}<0,05)$ so với các nghiệm thức còn lại. 
Bảng 6. Chỉ số biến thái của ấu trùng tôm càng xanh trong các nghiệm thức

\begin{tabular}{crrrr}
\hline \multirow{2}{*}{ Ngày } & \multicolumn{4}{c}{ Giai đoạn bổ sung đường cát } \\
\cline { 2 - 5 } & $\mathbf{2}$ & $\mathbf{4}$ & $\mathbf{6}$ & $\mathbf{8}$ \\
\hline 3 & $3,67 \pm 0,15^{\mathrm{a}}$ & $3,73 \pm 0,21^{\mathrm{a}}$ & $3,77 \pm 0,32^{\mathrm{a}}$ & $3,93 \pm 0,06^{\mathrm{a}}$ \\
6 & $5,23 \pm 0,40^{\mathrm{a}}$ & $4,77 \pm 0,40^{\mathrm{a}}$ & $5,00 \pm 0,01^{\mathrm{a}}$ & $5,07 \pm 0,12^{\mathrm{a}}$ \\
9 & $6,10 \pm 0,20^{\mathrm{a}}$ & $6,27 \pm 0,25^{\mathrm{a}}$ & $6,30 \pm 0,26^{\mathrm{a}}$ & $6,23 \pm 0,32^{\mathrm{a}}$ \\
12 & $6,70 \pm 0,44^{\mathrm{a}}$ & $7,03 \pm 0,31^{\mathrm{a}}$ & $6,70 \pm 0,60^{\mathrm{a}}$ & $6,60 \pm 0,53^{\mathrm{a}}$ \\
15 & $7,20 \pm 0,30^{\mathrm{a}}$ & $7,90 \pm 0,36^{\mathrm{a}}$ & $7,40 \pm 0,52^{\mathrm{a}}$ & $7,33 \pm 0,65^{\mathrm{a}}$ \\
18 & $8,50 \pm 0,30^{\mathrm{a}}$ & $8,63 \pm 0,23^{\mathrm{a}}$ & $8,47 \pm 0,61^{\mathrm{a}}$ & $8,57 \pm 0,21^{\mathrm{a}}$ \\
21 & $10,40 \pm 0,30^{\mathrm{b}}$ & $10,70 \pm 0,10^{\mathrm{c}}$ & $10,43 \pm 0,06^{\mathrm{b}}$ & $10,20 \pm 0,10^{\mathrm{a}}$ \\
\hline
\end{tabular}

Các giá trị cùng một hàng có ki tụ giống nhau thì khác biệt không có ý nghĩa thống kê $(p>0,05)$

\subsection{Tăng trưởng về chiều dài của ấu trùng tôm càng xanh}

Chiều dài của tôm ở giai đoạn 1,5 và 11 giữa các nghiệm thức khác biệt không có ý nghĩa thống kê ( $p>0,05)$. Chiều dài tôm PL1 ở nghiệm thức bổ sung đường cát từ giai đoạn 4 dài nhất và khác biệt có ý nghĩa thống kê $(p<0,05)$ so với nghiệm thức bổ sung đường cát từ giai đoạn $6(9,6 \mathrm{~mm})$ và nghiệm thức bổ sung đường cát từ giai đoạn $8(9,5 \mathrm{~mm})$, nhưng khác biệt không có ý nghĩa thống kê $(\mathrm{p}>0,05)$ so với nghiệm thức bổ sung đường cát từ giai đoạn $2(9,8$ $\mathrm{mm})$. Giai đoạn PL15 ở nghiệm thức bổ sung đường cát từ giai đoạn $4(11,4 \mathrm{~mm})$ tăng trưởng nhanh nhất, khác biệt có ý nghĩa thống kê $(\mathrm{p}<0,05)$ so với các nghiệm thức còn lại.

Bảng 7. Tăng trưởng chiều dài $(\mathrm{mm})$ của ấu trùng và hậu ấu trùng tôm càng xanh

\begin{tabular}{lrrrr}
\hline \multirow{2}{*}{ Giai đoạn } & \multicolumn{4}{c}{ Giai đoạn bổ sung đường cát } \\
\cline { 2 - 5 } & $\mathbf{2}$ & $\mathbf{4}$ & $\mathbf{6}$ & $\mathbf{8}$ \\
\hline Giai đoạn 1 & $2,0 \pm 0,0^{\mathrm{a}}$ & $2,0 \pm 0,0^{\mathrm{a}}$ & $2,0 \pm 0,0^{\mathrm{a}}$ & $2,0 \pm 0,0^{\mathrm{a}}$ \\
Giai đoạn 5 & $3,7 \pm 0,3^{\mathrm{a}}$ & $4,0 \pm 0,1^{\mathrm{a}}$ & $3,9 \pm 0,0^{\mathrm{a}}$ & $3,8 \pm 0,2^{\mathrm{a}}$ \\
Giai đoạn 11 & $7,7 \pm 0,3^{\mathrm{a}}$ & $8,1 \pm 0,1^{\mathrm{a}}$ & $7,7 \pm 0,0^{\mathrm{a}}$ & $7,9 \pm 0,3^{\mathrm{a}}$ \\
PL1 & $9,8 \pm 0,1^{\mathrm{bc}}$ & $9,9 \pm 0,1^{\mathrm{c}}$ & $9,6 \pm 0,2^{\mathrm{ab}}$ & $9,5 \pm 0,2^{\mathrm{a}}$ \\
PL15 & $10,6 \pm 0,3^{\mathrm{a}}$ & $11,4 \pm 0,1^{\mathrm{b}}$ & $10,7 \pm 0,3^{\mathrm{a}}$ & $1,0 \pm 0,7^{\mathrm{a}}$ \\
\hline
\end{tabular}

Các giá trị cùng một hàng có ki tư giống nhau thì khác biệt không có ý nghĩa thống kê $(p>0,05)$

\subsection{Tỷ lệ sống và năng suất}

Bảng 8 cho thấy tỷ lệ sống của các nghiệm thức dao động trong khoảng 44,5 đến 55,3\%. Tỷ lệ sống của tôm cao nhất là ở nghiệm thức bổ sung đường cát từ giai đoạn 4 khác biệt không có ý nghĩa thống kê so với nghiệm thức bổ sung đường cát từ giai đoạn 6 , nhưng khác biệt có ý nghĩa thống kê $(\mathrm{p}<0,05)$ so với các nghiệm thức còn lại. Điều này cho thấy việc bổ sung đường cát vào giai đoạn 4 là tốt nhất. Tỷ lệ sống của tôm trong thí nghiệm tương đối cao là nhờ các yếu tố môi trường trong quá trình ương luôn được kiểm soát tốt, đồng thời các hạt biofloc lơ lửng trong nước là nhân tố chính hạn chế sự ăn nhau của tôm.

Bảng 8. Tỷ lệ sống và năng suất của tôm PL15

\begin{tabular}{lrrrr}
\hline \multirow{2}{*}{ Chỉ tiêu } & \multicolumn{4}{c}{ Nghiệm thức bổ sung đường cát từ giai đoạn } \\
\cline { 2 - 5 } & $\mathbf{2}$ & $\mathbf{4}$ & $\mathbf{6}$ & $\mathbf{8}$ \\
\hline Tỷ lệ sống $(\%)$ & $44,5 \pm 3,5^{\mathrm{a}}$ & $55,3 \pm 1,9^{\mathrm{c}}$ & $52,9 \pm 2,6^{\mathrm{bc}}$ & $49,6 \pm 2,9^{\mathrm{ab}}$ \\
Năng suất $\left(\mathrm{PL} / \mathrm{m}^{3}\right)$ & $26.700 \pm 2.086^{\mathrm{a}}$ & $33.160 \pm 1.153^{\mathrm{c}}$ & $31.760 \pm 1.546^{\mathrm{bc}}$ & $29.780 \pm 1.740^{\mathrm{ab}}$ \\
\hline
\end{tabular}

Các giá trị cùng một hàng có kí tụ giống nhau thì khác biệt không có ý nghĩa thống kê (p>0,05)

Năng suất của PL15 được trình bày ở Bảng 8 , cũng giống như tỷ lệ sống, năng suất của tôm cao nhất là ở nghiệm thức bổ sung đường cát từ giai đoạn 4 khác biệt không có ý nghĩa thống kê so với nghiệm thức bổ sung đường cát từ giai đoạn 6 , nhưng khác biệt có ý nghĩa thống kê $(\mathrm{p}<0,05)$ so với các nghiệm thức còn lại, từ đó cho thấy bồ sung đường cát ở giai đoạn 2 (ngày thứ 2 bố trí tôm) sớm quá làm ảnh hưởng đến ấu trùng, còn bổ sung ở giai đoạn 8 trễ quá làm cho $\mathrm{TAN}, \mathrm{NO}_{2}^{-}$và mật độ vi khuẩn cao làm cho tỷ lệ sống và năng suất thấp ở 2 nghiệm thức này. Trần Ngọc Hải và ctv., (2018) cho rằng ương âu trùng tôm càng xanh trong hệ thống biofloc với các nguồn cacbon khác nhau cho năng suất PL-15 
dao động từ $18.411 \mathrm{con} / \mathrm{m}^{3}$ đến $24.569 \mathrm{con} / \mathrm{m}^{3}$, tỷ lệ sống 30,7 đến $40,9 \%$. So sánh kết quả cho thấy tỷ lệ sống và năng suất PL-15 của nghiên cứu này cao hơn vì nghiên cứu trước đây sử dụng bột gạo bố sung vào bể ương làm nước bị đục ảnh hường đến ấu trùng.

\section{KẾT LUẬN VÀ ĐỀ XUÂT}

\subsection{Kết luận}

Tăng trưởng về chiều dài, tỷ lệ sống và năng suất của PL-15 ở nghiệm thức bồ sung đường cát ở giai đoạn 4 là tốt nhất.

\section{2. Đề xuất}

Úng dụng bổ sung đường cát với tỷ lệ $\mathrm{C} / \mathrm{N}=17,5$ từ giai đoạn 4 trong ương ấu trùng tôm càng xanh vào thực tiễn sản xuất.

\section{LỜI CẢM ƠN}

Đề tài này được tài trợ bởi Dự án Nâng cấp Trường Đại học Cần Thơ VN14-P6 bằng nguồn vốn vay ODA từ Chính phủ Nhật Bản.

\section{TÀI LIỆU THAM KHẢO}

Ang K. J. (1985). The evolution of an enviromentally friendly hatchery technology for Udang Galah, the king of freshwater prawn and a limpse into future of aquaculture in 21 st century. University Pertanian Malaysia.

APHA, AWWA and WEF. (1995). Standard Methods for the Examination of Water and Wastewater, 19th Edition. APHA, AWWA VÀ WEF, FRANSON, M.A.H., (Ed.)

Avnimelech Y. (2012). Biofloc technology - a practical guide book. Second edition, The World Aquaculture Society, Baton Rouge, Louisiana, United States, $272 \mathrm{pp}$

Avnimelech, Y. (2015). Biofloc Technology - A Practical Guide Book, 3rd Edition. The World Aquaculture Society, Baton Rouge, Louisiana, United States.182 pp

Boyd, C., \& Zimmermann, S. (2000). Grow-out systems-water quality and soil management. Freshwater prawn culture: the farming of Macrobrachium rosenbergii. Blackwell Science, Oxford, UK, 221-238.

Châu Tài Tảo \& Trần Minh Phú. 2015. Ảnh hưởng của độ kiềm lên tăng trưởng và tỷ lệ sống của ấu trùng và hậu ấu trùng tôm càng xanh (Macrobrachium rosenbergii). Tạp chí Nông nghiệp và Phát triển nông thôn, (3+4): 93-99.

De Schryver, P., Crab, R., Defoirdt, T., Boon, N., \& Verstraete, W. (2008). The basics of bio-flocs technology: the added value for aquaculture. Aquaculture, 277(3-4), 125-137.

Đỗ Thị Thanh Hương \& Nguyễn Văn Tư. (2010). Một số vấn đề về sinh lý cá và giáp xác. Nhà xuất bản nông nghiệp. TP. Hồ Chí Minh.

Huys, G. (2002). Preservation of bacteria using commercial cryopreservation systems. Standard Operating Procedure. ASIARESISTPRES 2011-2002. Laboratory of Microbiology, Universiteit Gent, Belgium.

Lê Thanh Nghị, Phạm Minh Truyền, Châu Tài Tảo, Nguyễn Văn Hòa \& Trần Ngọc Hải. (2020). Ảnh hưởng của các nguồn cacbon lên tăng trưởng và tỷ lệ sống trong ương ấu trùng tôm càng xanh (Macrobrachium rosenbergii) bằng công nghệ biofloc. Tạp chi Khoa hoc Công nghệ Nông nghiệp Việt Nam, 5(114): 117-123.

Margarete, M., \& Wagner, C.V. (2006). Effect of nitrite on larval development of giant river prawn Macrobrachium rosenbergii. Original Research Article Aquaculture, 261(4): 1292-1298.

Nguyễn Thanh Phương, Trần Ngọc Hải, Trần Thị Thanh Hiền \& Marcy N. W. (2003). Nguyên lý và kỹ thuật sản xuất giống tôm càng xanh (Macrobrachium rosenbergii). Nhà xuất bản Nông nghiệp.

Phạm Minh Truyền, Lê Thanh Nghị, Châu Tài Tảo, Nguyễn Văn Hòa \& Trần Ngọc Hải. (2020). Nghiên cứu ương ấu trùng tôm càng xanh theo công nghệ biofloc với các tỉ lệ $\mathrm{C} / \mathrm{N}$ khác nhau. Tạp chí Khoa học Công nghệ Nông nghiệp Việt Nam, 1(110), 102-108.

Phạm Thị Tuyết Ngân, Trần Thị Kiều Trang \& Trương Quốc Phú. (2008). Biến động mật độ vi khuẩn trong ao nuôi tôm sú (Penaeus monodon) ghép với cá rô phi đỏ ở Sóc Trăng. Tạp chi Khoa học Đại học Cần Tho số chuyên đề Thủy sản quyển 1, 187-194.

Sandifer, P.A \& Smith T.I.J. (1995). Freshwater Prawns. In Hunner, J. and E.E. Brow (Eds.), Crustacean and Mollusk Aquaculture in the United State (pp. 63-125). Van Nostrand Rienhold, New York.

Tổng cục Thủy sản. (2018-3-02). Hội nghị triển khai kế hoạch phát triển ngành tôm năm 2018. https://tongcucthuysan.gov.vn/vi-vn/-tinvắn/doc-tin/009975/2018-03-02/hoi-nghi-trienkhai-ke-hoanh-phat-trien-nganh-tom-nam-2018

Trần Ngọc Hải, Phạm Văn Đầy \& Châu Tài Tảo. (2018). Nghiên cứu ương ấu trùng tôm càng xanh bằng công nghệ biofloc với các nguồn cacbon khác nhau. Tạp chi Khoa hoc Công nghẹ Nông nghiệp Việt Nam, 95(10), 125-129. 